\title{
Public transit, obesity, and medical costs: Assessing the magnitudes is
}

\author{
Ryan D. Edwards * \\ Queens College-City University of New York, 300-S Powdermaker Hall, 65-30 Kissena Blvd., Flushing, NY 11367, USA
}

Available online 18 October 2007

\begin{abstract}
Objective. This paper assesses the potential benefits of increased walking and reduced obesity associated with taking public transit in terms of dollars of medical costs saved and disability avoided.

Methods. I conduct a new analysis of a nationally representative U.S. transportation survey to gauge the net increase in walking associated with public transit usage. I translate minutes spent walking into energy expenditures and reductions in obesity prevalence, estimating the present value of costs and disability that may be avoided.

Results. Taking public transit is associated with walking 8.3 more minutes per day on average, or an additional 25.7-39.0 kcal. Hill et al. [Hill, J.O., Wyatt, H.R., Reed, G.W., Peters, J.C., 2003. Obesity and the environment: Where do we go from here? Science 299 (5608), 853-855] estimate that an increase in net expenditure of $100 \mathrm{kcal} /$ day can stop the increase in obesity in $90 \%$ of the population. Additional walking associated with public transit could save $\$ 5500$ per person in present value by reducing obesity-related medical costs. Savings in quality-adjusted life years could be even higher.

Conclusions. While no silver bullet, walking associated with public transit can have a substantial impact on obesity, costs, and well-being. Further research is warranted on the net impact of transit usage on all behaviors, including caloric intake and other types of exercise, and on whether policies can promote transit usage at acceptable cost.
\end{abstract}

(C) 2007 Elsevier Inc. All rights reserved.

Keywords: Obesity; Walking; Exercise; Transportation; Health expenditures

\section{Introduction}

A topic of much recent interest is the degree to which public transportation may increase exercise through walking. Other things equal, an increase in exercise could then improve health outcomes by lowering obesity, which many view as a looming but potentially manageable threat to public health (Hill et al., 2003; Olshansky et al., 2005; Preston, 2005). The "New Urbanism" movement of the 1990s, which continues today, calls for development of denser, grid-based neighborhoods in order to increase walking, bicycling, and use of transit (Cervero and Radisch, 1996). More recently, the entire January 2007 issue of Environment and Behavior was devoted to examining how the built environment relates to diet and exercise, and thus, to obesity. A joint study by the Transportation Research Board and

\footnotetext{
it All errors and opinions are those of the author alone and do not reflect the views of Queens College or the City University of New York.

* Fax: +1 7189975466 .

E-mail address: redwards@qc.cuny.edu.
}

the Institute of Medicine (2005) surveyed the state of knowledge regarding the built environment and physical activity. Although the study showed that the built environment, including access to public transit, can help or hinder the choice to engage in physical activity, it emphasized how the lack of good data and inadequate study design have significantly hampered inference.

Because residents typically select their communities, much remains unclear about the causal influence of environment on activity (Handy and Mokhtarian, 2005; Ogilvie et al., 2006). Longitudinal panel studies of relocated families and their behavior and outcomes, such as the nascent RESIDE project in Perth, Australia, are designed to untangle this issue. Without a clear sense of how urban form and the availability of mass transit can actually produce more exercise, researchers are limited in advocating specific policy interventions. Still, it is worth assessing the potential magnitudes of the influences of public transit on health, in order to gauge the plausible scope for policy and motivate further research.

The amount of additional physical activity associated with public transportation appears potentially significant. Besser and 
Dannenberg (2005) report that half of the roughly $3 \%$ of adults in the 2001 U.S. National Household Travel Survey (NHTS) who walked to and from public transit spent $19 \mathrm{~min}$ or more in total walking time, and almost a third exceeded $30 \mathrm{~min}$. Wener and Evans (2007) find that the average New York City train commuter walked about 9500 steps per day, roughly 2000 or $30 \%$ more steps than the average car commuter. Several papers associate form of transit with obesity directly. Frank et al. (2004) report that obesity around Atlanta, as measured by body mass index (BMI), is associated positively with time spent in cars and negatively with mixed land-use and with walking. Gordon-Larsen et al. (2005) reveal that non-overweight young adults in the Add Health survey were more likely to engage in active transportation like walking or bicycling, possibly in addition to taking public transit. Rundle et al. (2007) find BMI to be inversely associated with the density of bus stops, subway stops, and population around New York City.

However, is the additional walking associated with mass transit large enough to reduce obesity and associated health care costs? If yes, by how much? In this paper, I address this question by modeling daily time spent walking based on characteristics including transit use, and I then translate those differences into extra net energy expenditure and reductions in obesity.

\section{Methods}

\section{Estimating additional walking associated with public transit}

The quantity of interest is the additional amount of physical activity associated with taking public transit as opposed to driving. Wener and Evans (2007) measure this directly by asking a sample of car and train commuters around New York City to wear pedometers, and then comparing total steps for each group. No comparable study exists at the national level, but the 2001 National Household Travel Survey (U.S. Dept. of Transportation and Federal Highway Administration, 2001) contains similar data that are nationally representative.

Part of the 2001 NHTS included a daily travel diary in which household respondents were asked to self-report all trips, their purposes, starting and ending times, and the means of transportation during an assigned travel day. Individuals or their proxies were asked to fill out the travel diaries on their travel day, and then to relay that information during follow-up telephone interviews. The goal was to obtain travel information for each and every member of the household, but when members were unavailable, their trips went unmeasured. Walking trips undertaken for any reason, whether part of daily commutes, chores or errands, recreation or exercise, were part of the universe of daily trips recorded, as were bicycle trips. No other forms of physical activity were directly measured, but trips were also classified by purpose and could include trips to the gym, to exercise, or to play sports. All legs of all trips on the travel day were categorized by means of transportation. I define a public transit user as anyone who reports using it for any reason during the travel day.

Walking time in the NHTS is a limited measure of total physical activity in at least three respects. First, and most obviously, physical activity other than bicycling and walking goes unmeasured. Second, because the survey covers only one travel day per individual, it cannot measure behavior on other days that may be related. If a transit user walks more on Monday through Friday, she may choose to walk less on Saturday and Sunday because she is worn out. Third, selfreported walking time may not be a good objective measure of walking. As reviewed by Tudor-Locke and Myers (2001), the literature examining objective and subjective measures of walking typically reveals that individuals underreport total walking. To address the first two limitations, I explore the available information on other exercise in the NHTS, and I also examine how excluding weekend trips affects the results. The third limitation will bias my estimate of additional walking if under-reporting is correlated with public transit use. This seems unlikely but is untestable. I can only compare my estimates to those of Wener and Evans (2007), who collect objective measures of extra walking using pedometers.

I constructed total reported daily walking in minutes for each individual in the NHTS, and then I estimated the following model for individual $i$ :

walktime $_{i}=\alpha_{i}+\beta$ pubtrans $_{i}+\vec{B} \cdot \vec{X}_{i}+\varepsilon_{i}$,

where $\alpha_{i}$ is a fixed effect based on geography, pubtrans is a dummy variable indicating public transit use, $\vec{X}_{i}$ is a vector of socioeconomic and demographic controls, and $\varepsilon_{i}$ is a white-noise error. I interpret $\beta$ as the additional walking associated with transit use.

Estimation is complicated by several concerns. Because public transit use is a choice, endogeneity may render estimates of $\beta$ biased and inconsistent. With neither a controlled experiment nor good instrumental variables, little can be done other than to acknowledge this problem and work toward improving future study design. A more tractable problem is the fact that walktime exhibits severe response pooling, with $85 \%$ of NHTS respondents reporting no walking at all. (Table 1 reports characteristics of the weighted sample.) I therefore estimate Eq. (1) using the Tobit, a standard model for dealing with truncated data.

The version of the dataset I downloaded from the Inter-university Consortium for Political and Social Research contains a total of 140,915 individuals with at least partial travel diaries. Roughly 50,000 completed the entire survey and thus also have a sample weight. Sample weights were calculated based on the characteristics of all sampled households and Census data, where controls included geographic, socioeconomic, and demographic variables. For comparability to Besser and Dannenberg (2005), I define covariates similarly and restrict my analysis to respondents 18 years old and over. Of the 105,942 individuals in the adult subsample, 39,782 filled out the entire survey and have a sample weight, and 28,771 records contain all covariates.

\section{Estimating changes in obesity based on walking}

I convert my estimate of $\beta$, minutes of additional walking, into reductions in obesity prevalence in three steps. First, I translate minutes of walking into kilocalories (kcal) of energy expended using the basal metabolic rates (BMR) reported by Morabia and Costanza (2004): slow walking expends $3.1 \mathrm{kcal} / \mathrm{min}$, moderate walking $3.9 \mathrm{kcal} / \mathrm{min}$, and fast walking $4.7 \mathrm{kcal} / \mathrm{min}$. Then I convert additional kilocalories expended into reductions in stored energy using the efficiency factor of 50\% cited by Hill et al. (2003). Finally, I match reductions in stored energy with percentiles of the empirical distribution of excess energy stored reported by Hill et al., who examine recent waves of the National Health and Nutrition Examination Survey (NHANES). The result is a percentage that represents the share of Americans for whom weight gain would be eliminated by the given amount of extra walking. This can also be interpreted as the percentage reduction in the percentage increase in obesity prevalence for the average American.

\section{Forecasting obesity prevalence}

My baseline forecast of obesity prevalence is a simple extrapolation of past trends in U.S. obesity rates since 1960. These statistics are reported by Flegal et al. (2002) and Ogden et al. (2006), who examine data from the 1960-1962 National Health Examination Survey (NHES) and subsequent NHANES waves. They are depicted in the left side of Fig. 1, which plots historical and projected adult obesity prevalence. I produce alternative forecasts of obesity prevalence by multiplying the baseline annual increase in obesity by the percentage for whom walking eliminates weight gain, which I estimate as described above.

\section{Estimating medical cost savings and other benefits}

Obesity is costly along several dimensions. Chronic illnesses such as diabetes and musculoskeletal disorder associated with obesity (Must et al., 1999) cost additional dollars of medical expenditure. These and other diseases also reduce the quality of life (Cutler and Richardson, 1997), and they can also shorten life (Olshansky et al., 2005).

I forecast total medical cost savings per person by first projecting obesity prevalence for each remaining year of the average U.S. citizen's life using the 
Table 1

Sample characteristics of adults in the 2001 National Household Travel Survey

\begin{tabular}{|c|c|}
\hline Variable & Average \\
\hline Age & 48.2 \\
\hline Male & $47.7 \%$ \\
\hline White & $83.4 \%$ \\
\hline African American & $5.7 \%$ \\
\hline Other race & $10.8 \%$ \\
\hline Hispanic & $6.3 \%$ \\
\hline Less than high school degree & $8.0 \%$ \\
\hline High school graduate & $55.9 \%$ \\
\hline College graduate & $27.2 \%$ \\
\hline Graduate or professional degree & $8.8 \%$ \\
\hline Household income & $\$ 65,473$ \\
\hline Homeownership & $80.2 \%$ \\
\hline \multicolumn{2}{|l|}{ Census division of residence: } \\
\hline New England & $5.5 \%$ \\
\hline Middle Atlantic & $13.0 \%$ \\
\hline East North Central & $18.4 \%$ \\
\hline West North Central & $9.1 \%$ \\
\hline South Atlantic & $18.1 \%$ \\
\hline East South Central & $5.8 \%$ \\
\hline West South Central & $8.7 \%$ \\
\hline Mountain & $7.5 \%$ \\
\hline Pacific & $14.0 \%$ \\
\hline Population per square mile, block group & 3933 \\
\hline Lives in an MSA with rail & $12.3 \%$ \\
\hline Number of household vehicles & 2.2 \\
\hline Total daily walking time (min) & 5.1 \\
\hline Total daily biking time (min) & 0.4 \\
\hline Any walking & $14.6 \%$ \\
\hline Any biking & $1.0 \%$ \\
\hline Used public transit & $2.7 \%$ \\
\hline Used bus & $2.0 \%$ \\
\hline Used rail & $0.9 \%$ \\
\hline Only reported walking & $1.9 \%$ \\
\hline Only reported walking, to work & $0.4 \%$ \\
\hline Reported trips to gym/exercise/play sports & $12.3 \%$ \\
\hline Sample size & 28,771 \\
\hline
\end{tabular}

The sample is adults age 18 years and over, and sample weights are used to adjust for representativeness and incomplete survey response. A user of public transit is defined as anyone who reported using public transit at any time during his or her travel day. The "Other" racial group includes those not listed and all those self-identifying as mixed-race. "Hispanic" derives from a separate ethnicity question. "College degree" includes the bachelor but not the associate. "Advanced degree" includes any graduate or professional degree. Household income is measured over the previous 12 months.

extrapolation technique and the intervention estimates described above. The Census Bureau estimates the median age in the United States to be about 36, and a person of that age can expect to live 46 more years (Bell and Miller, 2005). Next, I obtain estimates of additional medical costs associated with obesity, which are assessed by a number of researchers, including Allison et al. (1999), Sturm (2002), Finkelstein et al. (2003), and Lakdawalla et al. (2005). It is convenient to combine the estimates of Sturm, who examines additional costs under age 65, with those of Lakdawalla et al., who explore costs over 70. I translate each of their estimates into 2007 dollars by assuming an annual rate of real growth in per capita medical spending of $3 \%$, per Lakdawalla et al., plus an additional $2.7 \%$ per year in general price inflation, for total annual growth of $5.7 \%$ in the nominal amounts. Sturm's estimate becomes $\$ 650$ per year for those under 65, whereas that of Lakdawalla et al. becomes $\$ 46,000$ for ages 70 and over. I assume that additional spending between age 65 and 70 is $\$ 650$.

In my next steps, I follow the lead of Lakdawalla et al., who explain their assumptions about future cost growth and discounting in greater detail. First, I project additional real spending in each future year by assuming that real per capita costs grow $3 \%$ per year. In each year of the projection, I apply the forecast obesity prevalence rate to the additional per capita spending associated with obesity. Then I compute the present discounted value of future amounts using a rate of time discounting also equal to $3 \%$ per year. Finally, I allocate spending between public and private funding sources by assuming that all spending at ages under 65 is privately funded, whereas $92.3 \%$ of spending at 65 and over is public.

In addition to increased medical costs, obesity also threatens the quality of health and well-being, most notably later in life, and I measure these costs as well. Lakdawalla et al. (2005) and Reynolds et al. (2005) both argue that obese elderly can expect to live roughly the same number of remaining years as the non-obese, but that their quality of life will be eroded through obesity-related disability. Lakdawalla et al. expect obese 70 -year-olds to enjoy 4 years of disability-free life, or 2.8 fewer than the non-obese. Reynolds et al. estimate the obese will live more like 8 years free of disability, but still about 2 years less than the non-obese. I assume 2.5 fewer years of disability-free life for obese elderly, and I ignore impacts earlier in life, about which less is known. The value of a life-year spent in disability, or a quality-adjusted life-year (QALY) weight, is about $80 \%$ of a life-year in perfect health (Cutler and Richardson, 1997), and I use that factor along with estimates of the value of a life-year (Viscusi and Aldy, 2003) to gauge the welfare costs of obesity-related disability.

\section{Results}

\section{Additional walking through transit}

Table 1 describes the characteristics of the weighted NHTS sample of adults, where the observations are person-days. Typical respondents are nearly 50 years old, roughly split between men and women, predominantly white, and typically hold only high school degrees. Average household income in the dataset is roughly twice per capita income because the data file frequently includes both adults in a typical household. Eighty percent of respondents own their own home. The average population density among these respondents, at just under 4000 people per square mile, is relatively high and comparable to levels around San Diego, Sacramento, and Portland, OR. But

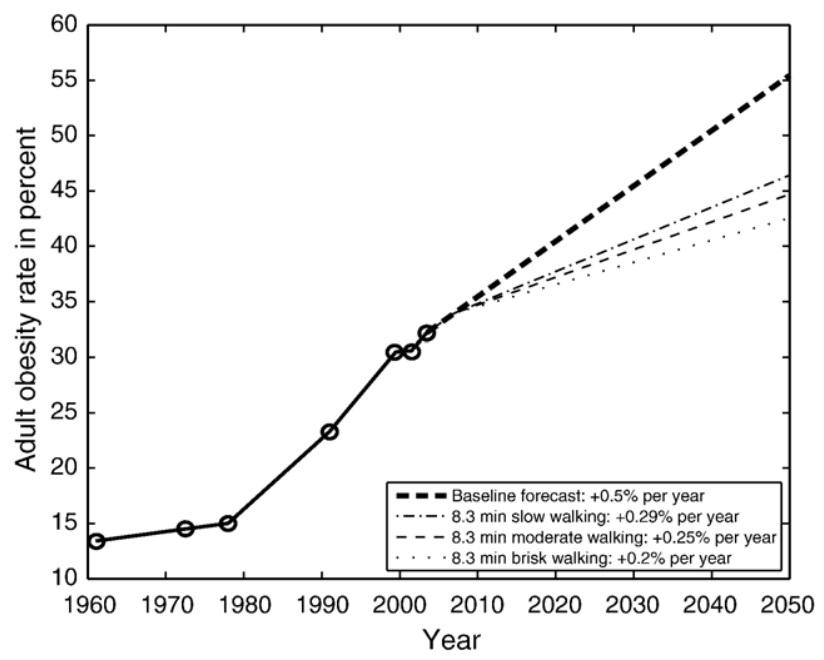

Fig. 1. Adult obesity rates in the United States, historical and projected. Data are the rate of obesity, defined as body mass index (BMI) 30 or greater, for the adult population measured in the National Health Examination Survey (NHES) and National Health and Nutrition Examination Survey (NHANES). Obesity rates are calculated by Flegal et al. (2002) and Ogden et al. (2006), appear as circles in the figure, and are plotted at the midpoint of the NHANES examination period. The dashed line represents a simple forward extrapolation from the most recent data point of the average annual increase in the rate, $0.5 \%$, which is estimated by ordinary least squares regression of all historical data on time. 
average rail access is low at only $12.3 \%$, which is also roughly the percentage in the Pacific division, and the average number of household vehicles is 2.2 .

Total walking time during the travel day averages just $5.1 \mathrm{~min}$, with only $14.6 \%$ reporting any walking at all. Time spent bicycling is even less common. Only about $2.7 \%$ reported any use of public transit, with most using buses as opposed to trains, although some used both. An almost equally large share, $1.9 \%$, reported walking as their sole means of transit on their travel day, but these were primarily recreational walkers rather than commuters. Although they reported little walking, which as discussed above may be an underestimate of actual walking, $12.3 \%$ of respondents reported a trip whose purpose was to facilitate engaging in physical exercise, like driving to the gym or to a softball game.

Table 2 presents the results of estimating Eq. (1), the model of daily walking time, using several alternative specifications. The first column presents simple ordinary least squares (OLS) estimates, which do not correct for the response heaping at zero minutes of walking time. The other five columns employ the Tobit estimation technique, which corrects for the $85 \%$ change of reporting zero walking. In each set of Tobit results, I report the marginal effects on the observed (truncated) variable rather than the underlying behavioral parameters, which are roughly equal to the reported coefficients divided by the probability of positive walking time, 0.15 . The latter would be only appropriate if zero walking times actually represented truncated negatives, which seems implausible.

Results are fairly robust across specifications, with public transit use significant at the $1 \%$ level in each and associated with between 8 and 10 additional minutes of walking per day. The Tobit specification produces a slightly smaller point estimate than OLS, and adding Census region fixed effects in column 3 lowers it a little more. Respondents in New England, the midAtlantic states, Mountain, and Pacific regions reported the most walking, whereas residents of states in East and West South Central regions, which are located along the Gulf, walked the least. Specifying state fixed effects yielded similar results.

When I included an indicator variable for train use, shown in the fourth column, a significant difference between train and bus commuters emerges. Users of public transit who do not use trains walk only an additional 6 min compared with non-users, whereas those who use trains walk another 4.5 min more, for a total of 10.5 extra minutes per day.

In the fifth column, I remove the train dummy and re-estimate the fixed effects model after excluding observations in which no other mode of transportation other than walking was reported. Public transit obviously cannot increase walking among those who report no other form than walking, so it is useful to estimate $\beta$ without them. As shown, dropping exclusive walkers increases the point estimate somewhat to 10.4 .

In the sixth and final column, I dropped weekend observations and found little change relative to column 3. My preferred estimate is the 8.3 additional minutes that appears in the third column.

\section{Other physical activity and transit}

The NHTS provides only two other measures of physical activity, bicycling time and trips taken to the gym, to exercise,

Table 2

Marginal effects of characteristics on total daily walking time in the 2001 National Household Transport Survey

\begin{tabular}{|c|c|c|c|c|c|c|}
\hline & 1 & 2 & 3 & 4 & 5 & 6 \\
\hline & OLS & Tobit & Tobit & Tobit & Tobit & Tobit \\
\hline Use public transit & $9.50(1.21)^{* * *}$ & $8.74(0.89)^{* * *}$ & $8.26(0.87)^{* * *}$ & $5.86(0.85)^{* * *}$ & $10.36(0.94)^{* * *}$ & $8.23(0.92)^{* * *}$ \\
\hline Use train & - & - & - & $4.50(1.31)^{* * *}$ & - & - \\
\hline Age & $0.02(0.01)^{* * *}$ & $0.02(0.01)^{* * *}$ & $0.02(0.01)^{* * *}$ & $0.02(0.01)^{* * *}$ & $0.02(0.00)^{* * *}$ & $0.03(0.01)^{* * *}$ \\
\hline Male & $-0.47(0.21)^{* *}$ & $-0.52(0.17)^{* * *}$ & $-0.51(0.17)^{* * *}$ & $-0.53(0.17)^{* * *}$ & $-0.44(0.15)^{* * *}$ & $-0.54(0.19)^{* * *}$ \\
\hline African American & $-0.85(0.49)$ & $-0.83(0.31)$ & $-0.57(0.32)^{*}$ & $-0.58(0.32)^{*}$ & $-0.92(0.29)^{* * *}$ & $-0.28(0.37)$ \\
\hline Other race & $-0.36(0.53)$ & $-0.53(0.38)$ & $-0.52(0.38)$ & $-0.52(0.38)$ & $-0.45(0.36)$ & $-0.42(0.43)$ \\
\hline Hispanic & $0.43(0.69)$ & $0.43(0.54)$ & $0.45(0.55)$ & $0.46(0.55)$ & $0.20(0.50)$ & $0.71(0.63)$ \\
\hline Less than high school degree & $-1.12(0.36)^{* * *}$ & $-0.81(0.29)^{* * *}$ & $-0.75(0.29)^{* * *}$ & $-0.73(0.29)^{* *}$ & $-0.97(0.27)^{* * *}$ & $-0.72(0.33)^{* *}$ \\
\hline College graduate & $1.00(0.29)^{* * *}$ & $1.09(0.24)^{* * *}$ & $1.11(0.24)^{* * *}$ & $1.11(0.24)^{* * *}$ & $1.04(0.22)^{* * *}$ & $0.80(0.26)^{* * *}$ \\
\hline Graduate or professional degree & $1.59(0.48)^{* * *}$ & $1.40(0.37)^{* * *}$ & $1.38(0.37)^{* * *}$ & $1.36(0.37)^{* * *}$ & $1.20(0.34)^{* * *}$ & $1.47(0.42)^{* * *}$ \\
\hline Log of Household Income & $-0.17(0.15)$ & $-0.09(0.11)$ & $-0.14(0.11)$ & $-0.16(0.11)$ & $0.09(0.10)$ & $-0.07(0.13)$ \\
\hline $\begin{array}{l}\text { Log population per square mile, } \\
\text { block group }\end{array}$ & $0.42(0.06)^{* * *}$ & $0.50(0.05)^{* * *}$ & $0.42(0.05)^{* * *}$ & $0.42(0.05)^{* * *}$ & $0.34(0.05)^{* * *}$ & $0.43(0.06)^{* * *}$ \\
\hline Own home & $-0.62(0.30)^{* *}$ & $-0.81(0.24)^{* * *}$ & $-0.72(0.24)^{* * *}$ & $-0.72(0.24)^{* * *}$ & $-0.15(0.22)$ & $-0.72(0.27)^{* * *}$ \\
\hline Number of household vehicles & $-0.78(0.10)^{* * *}$ & $-0.86(0.10)^{* * *}$ & $-0.86(0.10)^{* * *}$ & $-0.86(0.10)^{* * *}$ & $-0.57(0.09)^{* * *}$ & $-0.83(0.11)^{* * *}$ \\
\hline$N$ & 28,771 & 28,771 & 28,771 & 28,771 & 28,217 & 21,326 \\
\hline Census region fixed effects? & No & No & Yes & Yes & Yes & Yes \\
\hline $\begin{array}{l}\text { Include those who only } \\
\text { reported walking? }\end{array}$ & Yes & Yes & Yes & Yes & No & Yes \\
\hline Include weekends? & Yes & Yes & Yes & Yes & Yes & No \\
\hline
\end{tabular}

See notes to Table 1. Each column reports marginal effects from estimation of a model of daily walking time as shown in Eq. (1) in the text, with standard errors in parentheses. Column 1 reports ordinary least squares estimates, while columns 2-6 report Tobit estimates under various alternative specifications, where the reported marginal effects of each Tobit are the partial derivatives of the expected value of the observed (truncated) walking time variable. Asterisks denote statistical significance, with $* * *$ at the $1 \%$ level, $* *$ at $5 \%$, and $*$ at the $10 \%$ level. 
Table 3

The effect of additional walking on the present value of additional health care spending associated with obesity, 2007 dollars

\begin{tabular}{|c|c|c|c|c|c|c|}
\hline & $\begin{array}{l}\text { Additional energy } \\
\text { expenditure per } \\
\text { day (kcal) }\end{array}$ & $\begin{array}{l}\text { Annual growth } \\
\text { in obesity } \\
\text { prevalence }(\%)\end{array}$ & $\begin{array}{l}\text { Present value of } \\
\text { additional health } \\
\text { spending per person }\end{array}$ & $\begin{array}{l}\text { Present value of } \\
\text { savings relative } \\
\text { to baseline }\end{array}$ & $\begin{array}{l}\text { Present value of } \\
\text { additional public health } \\
\text { spending per person }\end{array}$ & $\begin{array}{l}\text { Present value of } \\
\text { public savings } \\
\text { relative to baseline }\end{array}$ \\
\hline Baseline & 0.0 & 0.5 & $\$ 34,200$ & - & $\$ 24,400$ & - \\
\hline \multicolumn{7}{|l|}{8.3 additional minutes of walking: } \\
\hline slowly (3.1 kcal/min) & 25.7 & 0.29 & $\$ 29,400$ & $\$ 4800$ & $\$ 20,600$ & $\$ 3800$ \\
\hline moderately (3.9 kcal/min) & 32.4 & 0.25 & $\$ 28,700$ & $\$ 5500$ & $\$ 19,900$ & $\$ 4500$ \\
\hline briskly (4.7 kcal/min) & 39.0 & 0.20 & $\$ 27,600$ & $\$ 6600$ & $\$ 19,000$ & $\$ 5400$ \\
\hline $\begin{array}{l}2000 \text { additional steps of walking, } \\
\text { or } 20.5 \mathrm{~min} \text { at } 3.9 \mathrm{kcal} / \mathrm{min}\end{array}$ & 80.0 & 0.07 & $\$ 24,700$ & $\$ 9500$ & $\$ 16,700$ & $\$ 7700$ \\
\hline $100 \mathrm{kcal} /$ day & 100.0 & 0.05 & $\$ 24,300$ & $\$ 9900$ & $\$ 16,400$ & $\$ 8000$ \\
\hline
\end{tabular}

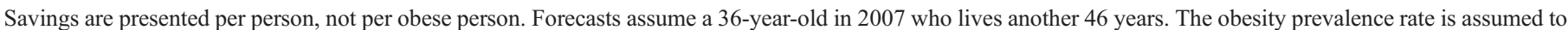

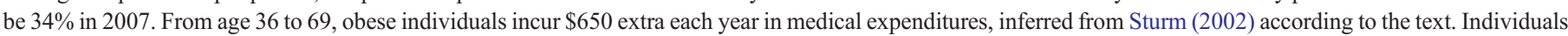

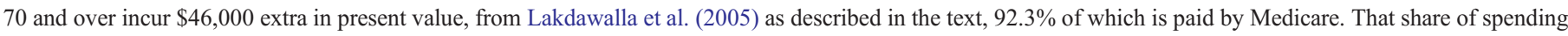
between age 65 and 70 is also categorized as public. All real medical spending grows at 3\% per year. The real discount rate is also $3 \%$ per year.

or to play sports. Bicycling is extremely rare in the NHTS, as shown in Table 1, and its association with public transit is small and of borderline significance. In a Tobit regression of bicycling time on the same covariates and region fixed effects listed in Table 2, I find transit use to be associated with just 0.2 fewer minutes of bicycling per day, significant at the $10 \%$ level.

Transit use is negatively associated with taking trips to go to the gym, to exercise, or to play sports. I ran a probit model on the probability of reporting any such trip on the covariates in Table 2, and I found transit use was associated with a reduction in the probability of trips for exercise of $2.7 \%$, significant at the $5 \%$ level (estimates not shown). Since only $12.3 \%$ of the sample reported any such trips (Table 1), this seems relatively large.

\section{Reductions in obesity}

Walking expends $3.1,3.9$, or $4.7 \mathrm{kcal} / \mathrm{min}$ depending on whether the walking is slow, moderate, or brisk (Morabia and Costanza, 2004), so the $8.3 \mathrm{~min}$ of additional walking associated with transit use could represent $25.7,32.4$, or 39.0 additional kcal expended each day. At a 50\% efficiency rate, those numbers translate into $12.9,16.2$, and 19.5 fewer kcal stored per day. The distribution of excess energy stored reported by Hill et al. (2003) reveals that these levels of additional expenditure could eliminate weight gain in approximately $43 \%$, $50 \%$, or $60 \%$ of the population.

\section{Obesity prevalence scenarios}

An OLS regression line through the historical obesity prevalence data in Fig. 1 has a slope equal to roughly $0.5 \%$ per year, significant at the $1 \%$ level. The baseline forecast, with future obesity prevalence increasing $0.5 \%$ each year, is shown at top-right in the figure. With 8.3 additional minutes of slow walking per day, $43 \%$ of the $0.5 \%$ annual increase is offset, leaving $0.29 \%$ per year. Similarly, moderate walking reduces growth to $0.25 \%$, whereas brisk walking leaves $0.2 \%$. These three scenarios are depicted in the right-hand side of Fig. 1 beneath the baseline projection.

\section{Medical cost and QALY savings}

Table 3 compares the present value of future medical costs in the baseline scenario to five alternatives: the three I have presented thus far; one based on the Wener and Evans (2007) estimate of 2000 extra steps; and for comparison, a scenario with 100 additional $\mathrm{kcal} /$ day expended, per the suggestion of Hill et al. (2003). At a rate of $0.04 \mathrm{kcal} / \mathrm{step}$ (Hill et al., 2003; Tudor-Locke and Bassett, 2004), 2000 steps translates into $80 \mathrm{kcal}$, or $20.5 \mathrm{~min}$ of moderate walking.

At baseline, I project that obesity will generate an extra $\$ 34,200$ in health costs per person, $\$ 24,400$ of which will be borne by Medicare and other public sources. An additional 8.3 min of daily walking could save $\$ 4800, \$ 5500$, or $\$ 6600$ in

Table 4

The effect of additional walking due to public transit on health status and its value by rate of future increase in obesity

\begin{tabular}{|c|c|c|c|c|}
\hline & $\begin{array}{l}\text { Average obesity prevalence } \\
\text { over age } 70(\%)\end{array}$ & $\begin{array}{l}\text { Expected QALYs lost } \\
\text { due to obesity }\end{array}$ & $\begin{array}{l}\text { Expected present value of } \\
\text { QALYs lost due to obesity }\end{array}$ & $\begin{array}{l}\text { Savings relative to } \\
\text { baseline }\end{array}$ \\
\hline Baseline & 54 & 0.27 & $\$ 54,000$ & - \\
\hline \multicolumn{5}{|l|}{8.3 additional minutes of walking: } \\
\hline moderately $(3.9 \mathrm{kcal} / \mathrm{min})$ & 44 & 0.22 & $\$ 44,000$ & $\$ 10,000$ \\
\hline briskly (4.7 kcal/min) & 42 & 0.21 & $\$ 42,000$ & $\$ 12,000$ \\
\hline $\begin{array}{l}2000 \text { additional steps of walking, } \\
\text { or } 20.5 \mathrm{~min} \text { at } 3.9 \mathrm{kcal} / \mathrm{min}\end{array}$ & 37 & 0.18 & $\$ 36,800$ & $\$ 17,200$ \\
\hline
\end{tabular}

See notes to Table 3. The assumed QALY weight of a life-year spent disabled is 0.8 . The present value of a life-year in perfect health is assumed to be $\$ 200,000$. 
present value per person depending on the intensity, and about $80 \%$ of the savings is public money. Walking the additional 2000 steps estimated by Wener and Evans could save $\$ 9500$ per person, and expending an extra $100 \mathrm{kcal} / \mathrm{day}$, as suggested by Hill et al., could save $\$ 9900$. Reducing obesity below current levels would save even more.

Table 4 presents estimates of QALYs lost and their value in each of the future scenarios, assuming obesity reduces disability-free life by 2.5 years. At baseline, I forecast a $54 \%$ chance of obesity over age 70 for the average 36-year-old, which is associated with a loss of 0.27 QALY. If a life-year spent in perfect health is worth $\$ 200,000$ (Viscusi and Aldy, 2003) and grows over time at roughly the real discount rate (Costa and Kahn, 2004), that represents a cost of $\$ 54,000$, or about $160 \%$ of the additional medical cost shown in Table 3. Walking 8.3 extra minutes could reduce obesity prevalence in old age to between $42 \%$ and $45 \%$, representing a savings of around $\$ 10,000$ or almost double the medical cost savings shown for that scenario in Table 3.

\section{Discussion}

The objective of this paper was to explore the potential benefits of shifting an average U.S. citizen from driving to using public transit. Savings in avoided medical expenses through increased physical activity and decreased obesity appear to be relatively large, around a present value of $\$ 5500$ per person. By comparison, a recent estimate suggests that quitting smoking could save between $€ 7600$ and 12,200 in present value per person depending on sex (Rasmussen et al., 2005), and a comparable dollar figure should be similar. Results hinge on an unknown that is difficult to estimate with great confidence: the additional physical activity associated with public transit. My best guess is that transit use involves 8.3 additional minutes of daily walking, but at least three caveats apply.

First, I cannot correct for the endogeneity of transit choice in cross-sectional data without good instrumental variables, and the true causal relationship between transit use and walking could be very different. It is unclear which way this may bias results; transit users could be people who enjoy living in urban areas and walking, or they could also be essentially forced to use transit and might offset the required energy expenditures by exercising less. A related issue that I have avoided addressing in this paper is the complicated relationship between obesity and public transit use. We want to consider public transit as an intervention to combat obesity, but this could get complicated if obesity affects the choice of transportation. Are people obese because they do not choose public transit, or do they not choose public transit because they are obese and it is difficult? It seems unlikely that anyone rationally chooses to be obese (Cutler et al., 2003), so anti-obesity policies in general are unlikely to trigger rational behavior that directly counteracts the intent, as might be an issue with anti-smoking policies if addiction is rational. But obesity is a state out of which it is costly to climb, or in this case walk, so the design of interventions should acknowledge the costs and probably seek to reduce them. These issues are related to the question of neighborhood selection in environmental studies, and much work remains to be done untangling them.

Second, and somewhat related, I have poor measures of physical activity other than walking, but the limited measures I have presented suggest some offsetting behavior. Bicycling is so rare that its tiny negative association with transit use is of limited importance. But what are we to make of less frequent trips to the gym among transit users? McDonald and Moffitt (1980) suggest a decomposition of the Tobit coefficient that is worth exploring. The 8.3 additional minutes of walking associated with taking public transit can be decomposed into portions attributable to the associated change in minutes of walking given one is already walking, which is about 8.8 , times the share of the sample already walking, 0.15 , plus the expected amount of walking if one walks at all, about $33.2 \mathrm{~min}$ in this sample, times the change in the probability of walking associated with public transit use, which a probit regression reveals to be about 0.21 . The larger of these two additive pieces is clearly the latter, which is to say that getting people to walk at all appears in these data to be a key contribution of public transit. So while there may be a cost in the probability of going to the gym, on the order of $2.7 \%$, the $21 \%$ increase in the probability of walking seems large by comparison. Further, even if there is offsetting behavior, it could be rational and not a cause for concern. People who use transit could be getting the optimal amount of exercise without trips to the gym, whereas drivers may simply not be reporting their exercise. Although the low reporting of trips to exercise in the NHTS casts some doubt on this hypothesis, the data are not rich enough to tell.

Third, I cannot measure net energy expenditure, which is a function of caloric intake in addition to physical activity. It could be that public transit indeed causes more physical activity, but individuals offset the potential health effects by eating more. I have no way of testing this hypothesis in the data we currently have.

A more complete look at changes in total physical activity and other behavior associated with transit awaits further study. However, it is noteworthy that Wener and Evans (2007) reveal a considerably larger effect than mine, some 2000 additional steps or $20.5 \mathrm{~min}$. They examine entire weeks of readings on pedometer wearers who were instructed to remove them only at bedtime. Presumably only those activities not involving footsteps went unmeasured. My estimate of $8.3 \mathrm{~min}$ is also considerably less than the 23-24 min of transit-related walking reported by Besser and Dannenberg (2005). They examined the self-reports of 3312 NHTS respondents who walked the entire way to and from public transit, meaning they did not measure individuals who use mixed modes in getting to or from transit, who probably walk less and whom I measured as transit users. Besser and Dannenberg also did not measure other walking during the day, which could be lower among transit users. Regarding the difference between my estimate and the results of Wener and Evans, mine could understate the true impact of transit use on walking if walking was significantly under-reported by transit users in the NHTS. It could also be the case that the sampled New York train commuters walked more than train commuters elsewhere, perhaps because $79 \%$ of them were college graduates. 
A somewhat less important component of my analysis is the underlying forecast of obesity prevalence. Although estimates of savings relative to baseline depend critically on the intervention, they are more or less independent of the choice of the baseline. I have chosen a simple linear extrapolation of the historical trend, which has been a $0.5 \%$ linear rate of increase since the inception of the NHES/NHANES survey in 1960. This is half the $1 \%$ rate suggested by Hill et al. (2003), who based it on statistics from the 1988-1994 and 1999-2000 waves of the NHANES that are rounded to the nearest whole percent. Since 1976 , a linear trend is closer to $0.7 \%$, but that ignores two previous data points. To be sure, extrapolating past linear trends forward is a risky enterprise, especially when the variable in question is a prevalence rate that must lie between zero and one and could be even more limited. But there is currently no evidence of an upper or lower bound on obesity prevalence, which varies considerably over time and space. According to the Global InfoBase of the World Health Organization, obesity prevalence is approaching $80 \%$ in parts of Polynesia. My baseline forecast results in a prevalence of about $55 \%$ by 2050 , which seems plausible given international trends.

Reduced obesity through walking is only one of a number of potential gains from increased use of public transit. Air pollution is a health hazard that is reduced when public transit usage increases. Users of public transit face much lower rates of injury and death, and increased use should reduce the hazards faced by motorists and pedestrians. Because public transit is more affordable, its availability can improve access to care and outcomes for vulnerable groups such as low-income pregnant women (Evans and Lien, 2005). Substituting public transit for car commuting probably reduces stress (Wener et al., 2006). These separate pathways through which transit may influence health warrant further investigation, but I leave a broader treatment to future efforts.

I also leave for future efforts several questions that are very tricky to answer. We do not know how to entice an individual to switch from car commuting to public transit, how to extend public transportation into underserved areas, and how high the marginal costs of these activities are relative to these potential marginal benefits I have outlined. Non-users of transit presumably face costs that are high enough to dissuade use. If required to use public transit, or even if prompted to do so through higher taxes and user costs, individuals may face substantial welfare costs that could easily exceed the benefits I have estimated. Dardis and Keane (1995) have assessed welfare costs of quitting smoking among rationally addicted smokers; we need a similar analysis of transportation choices.

\section{Conclusion}

Use of public transit is associated with more walking, by about 8.3 extra minutes per day. This is not enough walking to halt the spread of obesity, but it could substantially reduce it. The present value of medical expenditure savings per person could be $\$ 5500$, while the value of reduced disability could be even greater.

\section{References}

Allison, D.B., Zannolli, R., Narayan, K.M.V., 1999. The direct health care costs of obesity in the United States. Am. J. Publ. Health 89 (8), 1194-1199.

Bell, F.C., Miller, M.L., August 2005. Life tables for the United States Social Security area, 1900-2100. Actuarial Study No. 120, Office of the Chief Actuary, Social Security Administration.

Besser, L.M., Dannenberg, A.L., 2005. Walking to public transit: steps to help meet physical activity recommendations. Am. J. Prev. Med. 29 (4), 273-280.

Cervero, R., Radisch, C., 1996. Travel choices in pedestrian versus automobile oriented neighborhoods. Transp. Policy 3 (3), 127-141.

Costa, D.L., Kahn, M.E., 2004. Changes in the value of life, 1940-1980. J. Risk Uncertain. 29 (2), 159-180.

Cutler, D.M., Richardson, E., 1997. Measuring the health of the U.S. population. Brookings Pap. Econ. Act., Microecon. 217-271.

Cutler, D.M., Glaeser, E.L., Shapiro, J.M., 2003. Why have Americans become more obese? J. Econ. Perspect. 17 (3), 93-118 (Summer).

Dardis, R., Keane, T., 1995. Risk-benefit analysis of cigarette smoking: public policy implications. J. Consum. Aff. 29 (2), 351-367.

Evans, W.N., Lien, D.S., 2005. The benefits of prenatal care: evidence from the PAT bus strike. J. Econom. 125 (1-2), 207-239.

Finkelstein, E.A., Flebelkorn, I.C., Wang, G., 2003. National medical spending attributable to overweight and obesity: how much, and who's paying? Health Aff. W3, 219-226 (14 May).

Flegal, K.M., Carroll, M.D., Ogden, C.L., Johnson, C.L., 2002. Prevalence and trends in obesity among U.S. adults, 1999-2000. J. Am. Med. Assoc. 288 (14), 1728-1732.

Frank, L.D., Andersen, M.A., Schmid, T.L., 2004. Obesity relationships with community design, physical activity, and time spent in cars. Am. J. Prev. Med. 27 (2), 87-96.

Gordon-Larsen, P., Nelson, M.C., Beam, K., 2005. Associations among active transportation, physical activity, and weight status in young adults. Obes. Res. 13 (5), 868-875 (May).

Handy, S., Mokhtarian, P., 2005. Which comes first? The neighborhood or the walking? Access 26, 16-21 (Spring).

Hill, J.O., Wyatt, H.R., Reed, G.W., Peters, J.C., 2003. Obesity and the environment: where do we go from here? Science 299 (5608), 853-855.

Lakdawalla, D.N., Goldman, D.P., Shang, B., 2005. The health and cost consequences of obesity among the future elderly. Health Aff. 24 (S2) (W5-R30-R41).

McDonald, J.F., Moffitt, R.A., 1980. The uses of Tobit analysis. Rev. Econ. Stat. 62 (2), 318-321.

Morabia, A., Costanza, M.C., 2004. Does walking 15 minutes per day keep the obesity epidemic away? Simulation of the efficacy of a populationwide campaign. Am. J. Publ. Health 94 (3), 437-440 (March).

Must, A., Sadano, J., Coakley, E.H., Field, A.E., Colditz, G., Dietz, W.H., 1999 The disease burden associated with overweight and obesity. J. Am. Med. Assoc. 282 (16), 1523-1529.

Ogden, C.L., Carroll, M.D., Curtin, L.R., McDowell, M.A., Tabak, C.J., Flegal, K.M., 2006. Prevalence of overweight and obesity in the United States. J. Am. Med. Assoc. 295 (13), 1549-1555.

Ogilvie, D., Mitchell, R., Mutrie, N., Petticrew, M., Platt, S., 2006. Evaluating health effects of transport interventions: methodologic case study. Am. J. Prev. Med. 31 (2), 118-126 (August).

Olshansky, S.J., Passaro, D.J., Hershow, R.C., et al., 2005. A potential decline in life expectancy in the United States in the 21 st century. N. Engl. J. Med. 352 (11), 1138-1145 (17 March).

Preston, S.H., 2005. Deadweight?-The influence of obesity on longevity. N. Engl. J. Med. 352 (11), 1135-1137 (March 17).

Rasmussen, S.R., Prescott, E., Sørensen, T.I., Søgaard, J., 2005. The total lifetime health cost savings of smoking cessation to society. Eur. J. Public Health 15 (6), 601-606.

Reynolds, S.L., Saito, Y., Crimmins, E.M., 2005. The impact of obesity on active life expectancy in older American men and women. Gerontologist 45 (4), 438-444 (August).

Rundle, A., Roux, A.V.D., Freeman, L.M., Miller, D., Neckerman, K., Weiss, C.C., 2007. The urban built environment and obesity in New York City: a multilevel analysis. Am. J. Health Promot. 21 (4 Supplement), 326-334 (March/April). 
Sturm, R., 2002. The effects of obesity, smoking, and drinking on medical problems and costs. Health Aff. 21 (2), 245-253 (Mar/Apr).

Transportation Research Board, 2005. Does the Built Environment Influence Physical Activity? TRB Special Report, vol. 282. Transportation Research Board, Washington, DC.

Tudor-Locke, C.E., Myers, A.M., 2001. Methodological considerations for researchers and practitioners using pedometers to measure physical (ambulatory) activity. Res. Q. Exerc. Sport 72 (1), 1-12.

Tudor-Locke, C., Bassett Jr., D.R., 2004. How many steps/day are enough? Preliminary pedometer indices for public health. Sports Med. 34 (1), $1-8$.
U.S. Dept. of Transportation, Federal Highway Administration, 2001. National Household Travel Survey. Rockville, MD: Westat/Farmington Hills, MI: Morpace [producers], 2002. Ann Arbor, MI: Inter-university Consortium for Political and Social Research [distributor], 2004.

Viscusi, W.K., Aldy, J.E., 2003. The value of a statistical life: a critical review of market estimates throughout the world. J. Risk Uncertain. 27 (1), 5-76.

Wener, R.E., Evans, G.W., 2007. A morning stroll: levels of physical activity in car and mass transit commuting. Environ. Behav. 39 (1), 62-74.

Wener, R.E., Evans, G.W., Lutin, J., 2006. Leave the driving to them: comparing stress of car and train commuters. American Public Transit Association Rail Conference, New York (June 11-14, 2006). 